AARP INTERNATIONAL THE JOURNAL

VOLUME 11 - 2018 EDITION

AARP

Real Possibilities

\title{
From the Editor: AARP The Journal 2018
}

By Jonathan Stevens 
Dr. Ethel Percy Andrus, a retired high school principal, founded AARP in 1958 to promote her philosophy of productive aging. In 1963, Dr. Andrus established an international presence for AARP, and though it has taken many different forms since then, AARP International has continued to develop networks and form coalitions within the worldwide aging community, promoting the well-being of older persons through advocacy, education, and service.
Now, as we prepare to celebrate our $60^{\text {th }}$ anniversary, it is fitting that we introduce a re-designed version of AARP's global thought leadership publication, The Journal. In addition to a broad set of conversations on the opportunities and challenges found in an aging world, we are focusing attention on a set of stories from a single country. As the world's first "super-aged" nation, Japan is a logical choice for this new feature.

In the following pages, we look beyond the research reports and data tables to instead meet and engage the people of Japan. As demographic trends shift critical elements of Japan's society, AARP leveraged its relationships in-country to choose sites in Tokyo, Akita City, and Fukuoka that offer compelling stories about people, businesses, and organizations confronting and embracing longevity. We hope you enjoy this nuanced portrait of Japan's aging challenges and innovations.

In addition to our special feature on Japan, the 2018 edition of The Journal offers insights on wealth, health and your whole self - by looking across towns and around the world for creative responses to current trends in global longevity. AARP CEO Jo Ann Jenkins sets the scene by describing our worldwide efforts to broaden the impact of Disrupt Aging and change the conversation about what it means to grow older. She examines how we will continue to elevate the mission and vision of our founder through international engagement and exchange.

The recently launched Living100 project seeks to spark a conversation and asks some provocative questions. What do longer lifespans mean for us and for future generations? How can we address disparities in race, gender, income, education and geography that are often a matter of life and death? And most importantly, how can we challenge our mindsets and attitudes about aging so that we are not only living longer, but making the most of our extra time? 
The Journal takes on these questions and explores the best practices and common challenges that bring us together:

- Angel Gurría, Secretary-General of the Organisation for Economic Co-operation and Development, offers insights on the future of work and policies that promote older worker employment and reduce inequalities in later life.

- As people get older, their care needs will become increasingly complex. Justin Derbyshire, Chief Executive of HelpAge International, examines programs that ensure healthy lives and promote well-being for people of all ages.

- Brain health is a key factor in successful aging. AARP's Sarah Lock and James Goodwin, Chief Scientist of Age UK from the Global Council on Brain Health, offer insights and recommendations to reduce the risk of cognitive decline.

This edition of The Journal also spotlights how the accelerating combination of aging and urbanization calls for accessible communities that support aging in place. First, New York Governor Andrew Cuomo shares how some of the most evolved age-friendly projects are emerging from state and local stakeholders. Second, we explain how Sharjah in the United Arab Emirates is becoming the first age-friendly city in the Arab world. Finally, "Where We Live" from AARP's Nancy LeaMond showcases communities where people of all ages can thrive.

Throughout this anniversary edition, we are excited to look ahead at the creative ways we can choose to live and age. From Disrupt Aging to Living100, our goal is to shift hearts, minds, and markets away from the mentality that aging is a burden - and towards a more accurate assessment that an aging world offers new opportunities.

We at The Journal invite you to seize these fortunes with us.

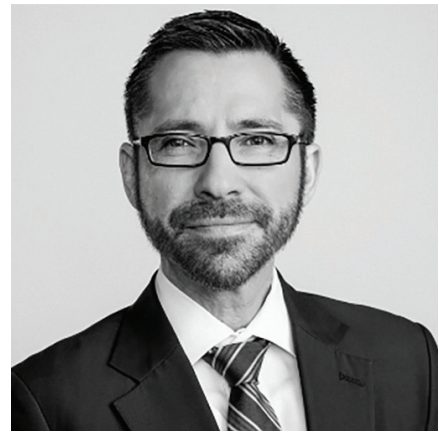

Jonathan Stevens SENIOR VICE PRESIDENT, AARP GLOBAL THOUGHT LEADERSHIP 
AARP International engages global stakeholders to spark solutions that strengthen communities, protect the vulnerable and enable people around the world to pursue their goals and dreams. Working with governments, civil society and the private sector, we are focused on enhancing the quality of life for people as they age. We serve as the global voice for AARP, a social change organization with a membership of more than 37 million.

THE JOURNAL ONLINE

aarpinternational.org/journal

AARP INTERNATIONAL ONLINE

aarpinternational.org

FACEBOOK

facebook.com/aarpintl

TWITTER

@aarpintl

CONTACT

AARP International

601 E Street, NW

Washington, DC 20049

United States

T +1 2024342398

E international@aarp.org

AARP International: The Journal is a publication of AARP. The views expressed herein do not necessarily represent policies of AARP and should not be construed as endorsements. The mention of a product or service herein is solely for information to our readers and may not be used for any commercial purpose. AARP, which was established in 1958, is a nonprofit, nonpartisan organization with tens of millions of members ages 50 and older. State offices are located in all 50 states, the District of Columbia, Puerto Rico, and the Virgin Islands.

January 2018

()2018, AARP

Reprinting with permission only. 